\title{
Evaluation of risk factors for dental caries from 6 to 8 years old children
}

\author{
Seiko Katsumura*1, Fusao Nishikawara*2, Yoh Tamaki*2,3,4, Hidenori Yamada*3, Yoshiki Nakamura*2,5, \\ Keita Sato*6, Shinpei Tsuge ${ }^{* 7}$, Yoshiaki Nomura*2 and Nobuhiro Hanada*2 \\ *1 Department of Anatomy, Tsurumi University School of Dental Medicine \\ 2-1-3 Tsurumi, Tsurumi-ku, Yokohama 230-8501, JAPAN \\ *2 Department of Oral Health, National Institute of Public Health \\ 2-3-6 Minami, Wako, Saitama 351-0197, JAPAN \\ *3 Department of Preventive Dentistry and Public Health, Tsurumi University School of Dental Medicine \\ 2-1-3 Tsurumi, Tsurumi-ku, Yokohama 230-8501, JAPAN \\ *4 Division of Oral Health, Department of Health Science, Kanagawa Dental College \\ 82 Inaoka-cho, Yokosuka, Kanagawa 238-8580, JAPAN \\ *5 Department of Orthodontics, Tsurumi University School of Dental Medicine \\ 2-1-3 Tsurumi, Tsurumi-ku, Yokohama 230-8501, JAPAN \\ ${ }^{*}$ Department of Forensic Medicine and Dentistry, Tsurumi University School of Dental Medicine \\ 2-1-3 Tsurumi, Tsurumi-ku, Yokohama 230-8501, JAPAN \\ *7 Tsuge Dental Clinic \\ 3384-5 Nakanohou-cho, Ena, Gifu 509-8231, JAPAN
}

\begin{abstract}
The aim of this study is to evaluate the risk factors for dental caries in young children in Japan. We studied 645 children attending 13 of 30 elementary schools in two areas in Japan. Total salivary level of mutans streptococci and lactobacilli were evaluated at pre-school medical check-ups. Other factors we evaluated included use of fluoride containing dentifrices, administration of fluoride varnish in a private dental office, having regular check-ups, use of mouthwash with fluoride, and daily intake of sweet juice or snacks. Oral examinations were carried out at annual medical check-ups with 2.5 years follow-up and finally 585 children were analyzed. By multivariate logistic regression analysis, only three factors; gender, salivary levels of mutans streptococci and the presence or absence of dental caries in deciduous teeth had a statistically significant correlation with the incidence of dental caries after 2.5 years of follow-up. At age 8 , odds ratios were 1.821 for female gender, 1.259 for mutans streptococci $\left(\log _{10} \mathrm{cfu} / \mathrm{ml}\right)$ and 2.262 for dental caries in deciduous teeth. Although the prevalence of dental caries has declined in Japan, mutans streptococci remain a risk factor.
\end{abstract}

Key words

Lactobacilli,

Risk factors,

Streptococcus mutans, Total streptococci

\section{Introduction}

The prevalence of dental caries has declined worldwide. Age-related prevalence does not fit a normal distribution because most subjects, especially children, have no dental caries, and because for those with dental caries, most have only one or two. However, there are children with many dental caries

Received on September 26, 2007

Accepted on February 18, 2008 and children at high risk ${ }^{1,2)}$. Therefore, risk factors for dental caries should be re-examined in order to inform public health strategies for the prevention of dental caries ${ }^{3)}$.

The etiology of dental caries has been investigated and risk factors have been proposed from both cross-sectional and longitudinal studies ${ }^{4,5}$. Most have been confirmed by epidemiological studies ${ }^{6,7)}$ which indicate that the presence of oral bacteria such as mutans streptococci (MS) and lactobacilli (LB) correlate with the prevalence of dental caries ${ }^{8,9}$. 


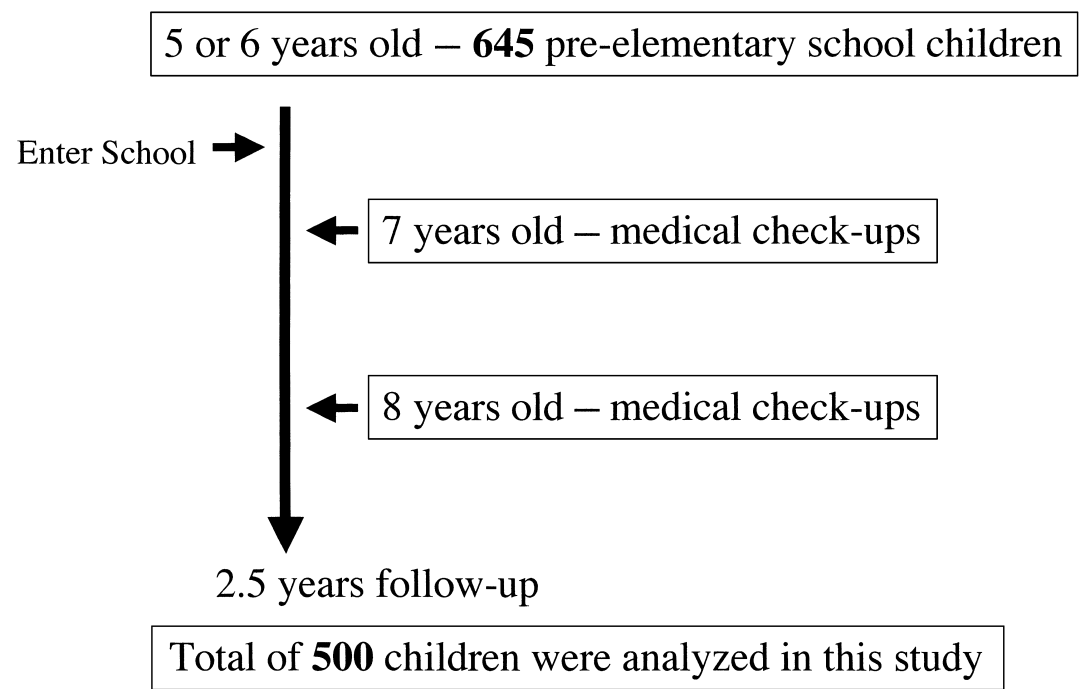

Fig. 1 The design for children was participated in this study

We started the study for 645 pre-school children. There were 125 children dropped out because the moving out or illnesses while for 2.5 follow-ups, total of 500 children were finally analyzed in this study.

Many published reports based on cohort studies demonstrate that MS and LB are risk factors for dental caries ${ }^{10-12)}$. Some studies indicate that a history of dental caries and oral levels of MS and their combinations are the best predictors of the incidence of dental caries $^{5)}$. Moreover, our previous study showed that salivary levels of MS and LB correlate with the prevalence of dental caries ${ }^{13)}$. This may be the reason why cariogenic bacteria may exist in the carious cavity ${ }^{14)}$ and are released into the saliva. In the present study, we evaluated school children at their annual medical check-up at school. We investigated the incidence of dental caries in each tooth and evaluated risk factors. The aim of this study was to analyze the contribution of these factors to the incidence of dental caries over 2.5 years of follow-up.

\section{Materials and Methods}

We planned the prospected cohort study to followup the elementary school children for 3 years to investigate the new incidence of the dental caries. This study design was approved by Ethic Committee of Tsurumi University School of Dental Medicine, Approval No. 408.

\section{Study population}

The study population was a sample from pre- elementary school children ( 5 or 6 years old) residing in the Ena and Nakatsugawa areas of Gifu Prefecture, Japan. The fluoride concentration of the drinking water in this area is less than $0.8 \mathrm{ppm}$ based on the water quality standards of Japan Waterworks Law ${ }^{15}$. Thirteen of the 30 elementary schools, nine from the Ena area and four from the Nakatsugawa area were sampled. Children and parents were informed of the survey in the mail that announced their entry into elementary school. A total of 645 children participated in this study. Twelve children dropped out before the base line examinations. After enter school, they had the dental examination in medical check-ups once a year. Finally, we analyzed the results for 500 children were checked-up at all of three times for 2.5 years (Fig. 1). The primary reasons for drop out were relocation and missed check-ups due to illness. We obtained clinical samples and completed questionnaires during the pre-school medical check-ups; we also obtained informed consent. Details are described in our previous report ${ }^{16)}$.

\section{Clinical examination and clinical samples}

Dentists conducted oral examinations under light using dental mirrors. Teeth conditions were scored as sound, decayed or filled. The decayed or filled teeth were identified based on WHO standard method and criteria ${ }^{17}$. Saliva samples were obtained by having subjects chew a gum base for 3 min that contained 
Table 1 Descriptive analysis of the prevalence of dental caries at each age

\begin{tabular}{|c|c|c|c|c|c|c|c|c|c|}
\hline & & \multirow{2}{*}{ Age } & \multicolumn{2}{|c|}{ Male } & \multicolumn{2}{|c|}{ Female } & \multirow{2}{*}{$P$-value } & \multicolumn{2}{|c|}{ Total } \\
\hline & & & mean & SD & mean & SD & & mean & SD \\
\hline \multirow{9}{*}{$\begin{array}{l}\text { Deciduous } \\
\text { teeth }\end{array}$} & \multirow{3}{*}{$\begin{array}{c}\text { Number of } \\
\text { remaining } \\
\text { teeth }\end{array}$} & 6 & 17.000 & 2.485 & 16.390 & 2.476 & 0.001 & 16.690 & 2.491 \\
\hline & & 7 & 14.160 & 2.231 & 13.220 & 2.336 & $<0.001$ & 13.670 & 2.325 \\
\hline & & 8 & 11.890 & 2.042 & 10.920 & 2.498 & $<0.001$ & 11.400 & 2.329 \\
\hline & \multirow{3}{*}{$\mathrm{d}$} & 6 & 1.010 & 1.678 & 1.110 & 2.093 & 0.762 & 1.060 & 1.894 \\
\hline & & 7 & 0.970 & 1.651 & 1.040 & 1.834 & 0.796 & 1.000 & 1.741 \\
\hline & & 8 & 0.980 & 1.624 & 0.940 & 1.722 & 0.458 & 0.960 & 1.671 \\
\hline & \multirow{3}{*}{$\mathrm{f}$} & 6 & 2.680 & 2.968 & 2.330 & 2.745 & 0.203 & 2.510 & 2.872 \\
\hline & & 7 & 2.830 & 2.836 & 2.450 & 2.547 & 0.215 & 2.640 & 2.698 \\
\hline & & 8 & 3.020 & 2.723 & 2.680 & 2.589 & 0.154 & 2.840 & 2.658 \\
\hline \multirow{12}{*}{$\begin{array}{c}\text { Permanent } \\
\text { teeth }\end{array}$} & \multirow{3}{*}{$\begin{array}{c}\text { Number of } \\
\text { remaining } \\
\text { teeth }\end{array}$} & 6 & 4.510 & 3.247 & 5.670 & 3.291 & $<0.001$ & 5.100 & 3.313 \\
\hline & & 7 & 8.770 & 2.732 & 9.660 & 2.591 & $<0.001$ & 9.240 & 2.689 \\
\hline & & 8 & 11.300 & 1.960 & 12.280 & 2.468 & $<0.001$ & 11.790 & 2.279 \\
\hline & \multirow{3}{*}{$\mathrm{D}$} & 6 & 0.010 & 0.141 & 0.030 & 0.220 & 0.322 & 0.020 & 0.185 \\
\hline & & 7 & 0.050 & 0.300 & 0.090 & 0.464 & 0.594 & 0.070 & 0.392 \\
\hline & & 8 & 0.090 & 0.463 & 0.170 & 0.606 & 0.021 & 0.130 & 0.540 \\
\hline & \multirow{3}{*}{ M } & 6 & 0.000 & 0.000 & 0.000 & 0.000 & 1.000 & 0.000 & 0.000 \\
\hline & & 7 & 0.000 & 0.000 & 0.000 & 0.000 & 1.000 & 0.000 & 0.000 \\
\hline & & 8 & 0.000 & 0.000 & 0.000 & 0.000 & 1.000 & 0.000 & 0.000 \\
\hline & \multirow{3}{*}{$\mathrm{F}$} & 6 & 0.040 & 0.298 & 0.030 & 0.261 & 0.790 & 0.030 & 0.279 \\
\hline & & 7 & 0.030 & 0.198 & 0.070 & 0.373 & 0.302 & 0.050 & 0.300 \\
\hline & & 8 & 0.090 & 0.358 & 0.130 & 0.446 & 0.287 & 0.110 & 0.404 \\
\hline
\end{tabular}

$\mathrm{D}(\mathrm{d})$ : decayed teeth in the permanent teeth (in deciduous teeth), M: missing teeth, $\mathrm{F}(\mathrm{f})$ : filling teeth

$P$-values were calculated the significant difference between male and female by Mann-Whitney $\mathrm{U}$ tests.

no taste or flavor additives, and salivary $\mathrm{pH}$ was evaluated using $\mathrm{pH}$-testing paper (Toyoroshi, Tokyo, Japan).

\section{Microbial procedures}

To estimate total streptococci, MS and LB in saliva, we performed microbial procedures according to the method described previously ${ }^{10,18)}$. The obtained saliva samples were vortexed for 30 seconds and diluted $1: 10^{2}-10^{4}$ in phosphate-buffered saline (PBS). Fifty microliters of samples were spread onto MitisSalivarius agar (MS: Difco, Tokyo, Japan) medium for total streptococci. We also used modified MSB agar medium ${ }^{19)}$ which is MS agar (Difco, Tokyo, Japan) supplemented with 20\% sucrose (Wako Pure Chemicals Co., Osaka, Japan), $20 \mathrm{mg} / \mathrm{m} l$ Yeast Extract (Becton Dikinson MD, USA), 0.25 U/m $l$ Bacitracin (Sigma, Inc., St. Louis, MO, USA), $10 \mathrm{mg} / \mathrm{ml}$ Colistin (Wako), $10 \mathrm{mg} / \mathrm{m} l$ Nalidixic Acid (Wako), $4 \mathrm{mg} / \mathrm{ml}$ Gramicidin (Sigma) for selective culture of MS, and Rogosa SLagar medium (Nippon Becton Dickinson Company, Ltd., Tokyo, Japan) for LB. These media were inoculated using an EDDY JET spiral system (Gunze Sangyo, Inc., Tokyo, Japan). After anaerobic incubation for MS and modified MSB agar media for 48 hours, LB for 72 hours, we counted the colonies to determine the number of bacteria per $\mathrm{m} l$ whole-saliva on each agar medium using a spiral systems counting grid (Spiral Colony Counter; Yoshikawa Kogyo Co. Ltd., Fukuoka, Japan).

\section{Questionnaires}

Questionnaires were distributed by mail along with an announcement of the requirement for school participation; questionnaires were collected at preschool medical check-ups. The questionnaires consisted of five items concerning fluoride use and diet. Fluoride use was evaluated by daily use of fluoride containing dentifrices (yes or no), a experience of 
Table 2 Descriptive analysis of the DMF for each age

\begin{tabular}{|c|c|c|c|c|c|c|c|c|c|c|c|c|c|c|c|c|c|c|c|c|c|c|c|}
\hline & & \multicolumn{2}{|l|}{ Teeth } & \multicolumn{2}{|l|}{7} & \multicolumn{3}{|c|}{6} & \multicolumn{3}{|c|}{5} & \multicolumn{3}{|c|}{4} & \multicolumn{3}{|c|}{3} & \multicolumn{3}{|c|}{2} & \multicolumn{3}{|c|}{1} \\
\hline & & Age & 6 & 7 & 8 & 6 & 7 & 8 & 6 & 7 & 8 & 6 & 7 & 8 & 6 & 7 & 8 & 6 & 7 & 8 & 6 & 7 & 8 \\
\hline \multirow{8}{*}{ Right } & \multirow{4}{*}{ Upper } & Not erupted & 500 & 500 & 500 & 246 & 62 & 19 & 500 & 498 & 492 & 499 & 492 & 454 & 500 & 500 & 486 & 490 & 364 & 138 & 362 & 110 & 21 \\
\hline & & Sound & 0 & 0 & 0 & 250 & 430 & 465 & 0 & 2 & 8 & 1 & 8 & 45 & 0 & 0 & 14 & 10 & 136 & 362 & 137 & 389 & 478 \\
\hline & & Decayed & 0 & 0 & 0 & 2 & 4 & 12 & 0 & 0 & 0 & 0 & 0 & 1 & 0 & 0 & 0 & 0 & 0 & 0 & 0 & 0 & 0 \\
\hline & & Filled & 0 & 0 & 0 & 2 & 4 & 4 & 0 & 0 & 0 & 0 & 0 & 0 & 0 & 0 & 0 & 0 & 0 & 0 & 1 & 1 & 1 \\
\hline & \multirow{4}{*}{ Lower } & Not erupted & 500 & 500 & 500 & 162 & 37 & 7 & 500 & 500 & 494 & 500 & 497 & 468 & 496 & 496 & 454 & 351 & 125 & 22 & 115 & 17 & 3 \\
\hline & & Sound & 0 & 0 & 0 & 332 & 448 & 450 & 0 & 0 & 5 & 0 & 3 & 30 & 4 & 4 & 46 & 149 & 375 & 478 & 385 & 483 & 496 \\
\hline & & Decayed & 0 & 0 & 0 & 3 & 8 & 23 & 0 & 0 & 0 & 0 & 0 & 0 & 0 & 0 & 0 & 0 & 0 & 0 & 0 & 0 & 0 \\
\hline & & Filled & 0 & 0 & 0 & 3 & 7 & 20 & 0 & 0 & 1 & 0 & 0 & 2 & 0 & 0 & 0 & 0 & 0 & 0 & 0 & 0 & 1 \\
\hline \multirow{8}{*}{ Left } & \multirow{4}{*}{ Upper } & Not erupted & 500 & 500 & 500 & 253 & 69 & 19 & 491 & 366 & 133 & 500 & 499 & 485 & 498 & 496 & 463 & 499 & 499 & 493 & 253 & 69 & 19 \\
\hline & & Sound & 0 & 0 & 0 & 240 & 417 & 464 & 9 & 134 & 367 & 0 & 1 & 15 & 2 & 4 & 37 & 1 & 1 & 7 & 240 & 417 & 464 \\
\hline & & Decayed & 0 & 0 & 0 & 1 & 7 & 9 & 0 & 0 & 0 & 0 & 0 & 0 & 0 & 0 & 0 & 0 & 0 & 0 & 1 & 7 & 9 \\
\hline & & Filled & 0 & 0 & 0 & 6 & 7 & 8 & 0 & 0 & 0 & 0 & 0 & 0 & 0 & 0 & 0 & 0 & 0 & 0 & 6 & 7 & 8 \\
\hline & \multirow{4}{*}{ Lower } & Not erupted & 500 & 500 & 500 & 157 & 40 & 7 & 352 & 118 & 23 & 496 & 496 & 447 & 499 & 493 & 458 & 500 & 498 & 490 & 361 & 119 & 23 \\
\hline & & Sound & 0 & 0 & 0 & 336 & 434 & 450 & 148 & 382 & 477 & 4 & 4 & 53 & 1 & 7 & 42 & 0 & 2 & 10 & 139 & 381 & 475 \\
\hline & & Decayed & 0 & 0 & 0 & 3 & 17 & 22 & 0 & 0 & 0 & 0 & 0 & 0 & 0 & 0 & 0 & 0 & 0 & 0 & 0 & 0 & 2 \\
\hline & & Filled & 0 & 0 & 0 & 4 & 9 & 21 & 0 & 0 & 0 & 0 & 0 & 0 & 0 & 0 & 0 & 0 & 0 & 0 & 0 & 0 & 0 \\
\hline
\end{tabular}

$\mathrm{n}=500$, total of children were check-up for 2.5 years. By the result of Table 1, subjects have no missing teeth at each age.

having had a fluoride varnish at a private dental office or at usual health care check-ups (yes or no) and daily use of mouthwash with fluoride (yes or no). The questionnaire on dietary sugar intake consisted of two items: the number instances of daily intake of sweet soft drink, and the daily intake of sweet snacks (once, twice, three times or more than four times).

\section{Statistical analysis}

Before the analysis for every check-up results, patients were divided into two groups; those free from dental caries, and those with at least one decayed or filled tooth (df teeth). As with microbiological factors, the bacteriological counts were $\log _{10^{-}}$ transformed prior to statistical analysis to normalize the variances. Logistic regression analysis was used to evaluate the crude or adjusted odds ratios and their associated $95 \%$ confidence intervals $(95 \% \mathrm{CI})$. To eliminate confounding factors, multiple logistic regression analysis was used.

\section{Results}

In this study, the DMFT (D; Decayed, M; Missing, F; Filled, T; Teeth) index at ages 6, 7 and 8 years were $0.050,0.120$ and 0.230 , respectively. The descriptive analysis of the dental caries conditions for both deciduous and permanent teeth is shown in Table 1. At ages 6 and 7, the incidence of dental caries showed no statistically significant differences between male and female $(P=0.303$ and $P=0.206$ in permanent teeth). However, at age 8 , females had more dental caries compared to males in permanent teeth and the difference was statistically significant $(P=0.021)$. When we compared dental caries in deciduous teeth of females at age 8 , index of caries in $\mathrm{d}, \mathrm{f}$ and $\mathrm{df}$ teeth were lower than in males. Table 2 shows a descriptive analysis for dental caries conditions for each tooth. As can be seen in this table, dental caries in incisors, canines and premolars rarely occurred until age 8 . Dental caries mainly occurred in the first molar teeth.

To investigate the risk factors for the incidence of dental caries, subjects were divided into two groups: the presence or absence of dental caries for their age. Logistic regression analysis was then carried out to calculate the crude and multivariate adjusted odds ratios. As shown in Table 3, at age 6 , no factors were associated with the incidence of new dental caries. At age 7, using the crude odds ratios, oral bacteria such as the salivary level of LB, total streptococci and MS had statistically significant correlations with the incidence of dental caries. At age 8, using the crude odds ratios, salivary $\mathrm{pH}$, the salivary level of LB, total streptococci, MS, 
Table 3 Crude odds ratios for the incidence of dental caries by logistic regression analysis

\begin{tabular}{|c|c|c|c|c|c|c|c|c|c|c|c|c|}
\hline \multirow[b]{3}{*}{ Saliva volume } & \multicolumn{4}{|c|}{6 years old } & \multicolumn{4}{|c|}{7 years old } & \multicolumn{4}{|c|}{8 years old } \\
\hline & \multirow{2}{*}{$\begin{array}{c}\begin{array}{c}\text { Crude } \\
\text { odds ratio }\end{array} \\
1.034\end{array}$} & \multicolumn{2}{|c|}{$95.0 \% \mathrm{CI}$} & \multirow{2}{*}{$\begin{array}{c}P \text {-value } \\
0.809\end{array}$} & \multirow{2}{*}{$\begin{array}{c}\begin{array}{c}\text { Crude } \\
\text { odds ratio }\end{array} \\
1.000\end{array}$} & \multicolumn{2}{|c|}{$95.0 \% \mathrm{CI}$} & \multirow{2}{*}{$\begin{array}{c}P \text {-value } \\
0.058\end{array}$} & \multirow{2}{*}{$\begin{array}{c}\begin{array}{c}\text { Crude } \\
\text { odds ratio }\end{array} \\
0.887\end{array}$} & \multicolumn{2}{|c|}{$95.0 \% \mathrm{CI}$} & \multirow{2}{*}{$\begin{array}{c}P \text {-value } \\
0.129\end{array}$} \\
\hline & & 0.786 & 1.361 & & & 1.000 & 1.000 & & & 0.760 & 1.035 & \\
\hline Salivary pH & 0.420 & 0.044 & 3.986 & 0.450 & 0.858 & 0.696 & 1.058 & 0.152 & 0.315 & 0.098 & 1.009 & 0.052 \\
\hline Lactobacilli (log) & 1.223 & 0.975 & 1.534 & 0.081 & 1.217 & 1.048 & 1.413 & 0.010 & 1.171 & 1.049 & 1.308 & 0.005 \\
\hline Total streptococci (log) & 2.551 & 0.376 & 17.282 & 0.337 & 5.129 & 1.386 & 18.989 & 0.014 & 3.064 & 1.137 & 8.252 & 0.027 \\
\hline S. mutans $(\log )$ & 1.402 & 0.983 & 1.530 & 0.062 & 1.259 & 1.038 & 1.526 & 0.019 & 1.387 & 1.175 & 1.637 & 0.000 \\
\hline S. mutans ratio & 1.032 & 0.986 & 1.081 & 0.177 & 1.027 & 0.993 & 1.062 & 0.116 & 1.045 & 1.018 & 1.072 & 0.001 \\
\hline Fluoride dentifrice & 2.394 & 0.895 & 6.401 & 0.082 & 0.676 & 0.335 & 1.363 & 0.273 & 0.882 & 0.526 & 1.481 & 0.636 \\
\hline Fluoride varnish & 0.830 & 0.481 & 1.430 & 0.501 & 0.952 & 0.672 & 1.347 & 0.780 & 1.055 & 0.812 & 1.371 & 0.688 \\
\hline Fluoride mouth rinse & 1.125 & 0.393 & 3.220 & 0.827 & 1.175 & 0.583 & 2.371 & 0.652 & 0.936 & 0.541 & 1.619 & 0.812 \\
\hline Juice intake & 1.098 & 0.598 & 2.017 & 0.763 & 1.092 & 0.726 & 1.643 & 0.672 & 1.370 & 1.013 & 1.855 & 0.041 \\
\hline Sweet snack intake & 1.019 & 0.477 & 2.177 & 0.961 & 0.822 & 0.486 & 1.390 & 0.465 & 0.991 & 0.670 & 1.466 & 0.965 \\
\hline Regular check-ups & 0.217 & 0.028 & 1.657 & 0.141 & 0.612 & 0.250 & 1.499 & 0.283 & 0.748 & 0.394 & 1.421 & 0.375 \\
\hline $\begin{array}{l}\text { Dental carries in } \\
\text { deciduous teeth }+/-\end{array}$ & 0.943 & 0.326 & 2.728 & 0.914 & 1.944 & 0.839 & 4.503 & 0.121 & 3.193 & 1.543 & 6.608 & 0.002 \\
\hline Gender & 1.370 & 0.513 & 3.660 & 0.529 & 1.468 & 0.760 & 2.835 & 0.253 & 1.799 & 1.080 & 2.996 & 0.024 \\
\hline
\end{tabular}

Table 4 Multivariate adjusted odds ratios for the incidence of the dental caries by logistic regression analysis

\begin{tabular}{|c|c|c|c|c|c|c|c|c|c|c|c|c|}
\hline \multirow[b]{3}{*}{ Saliva volume } & \multicolumn{4}{|c|}{6 years old } & \multicolumn{4}{|c|}{7 years old } & \multicolumn{4}{|c|}{8 years old } \\
\hline & \multirow{2}{*}{$\begin{array}{c}\begin{array}{c}\text { Adjusted } \\
\text { odds ratio }\end{array} \\
1.213\end{array}$} & \multicolumn{2}{|c|}{$95.0 \% \mathrm{CI}$} & \multirow{2}{*}{$\begin{array}{c}P \text {-value } \\
0.236\end{array}$} & \multirow{2}{*}{$\begin{array}{c}\begin{array}{c}\text { Adjusted } \\
\text { odds ratio }\end{array} \\
0.990\end{array}$} & \multicolumn{2}{|c|}{$95.0 \% \mathrm{CI}$} & \multirow{2}{*}{$\begin{array}{c}P \text {-value } \\
0.933\end{array}$} & \multirow{2}{*}{$\begin{array}{c}\begin{array}{c}\text { Adjusted } \\
\text { odds ratio }\end{array} \\
1.007\end{array}$} & \multicolumn{2}{|c|}{$95.0 \% \mathrm{CI}$} & \multirow{2}{*}{$\begin{array}{c}P \text {-value } \\
0.940\end{array}$} \\
\hline & & 0.881 & 1.670 & & & 0.782 & 1.253 & & & 0.839 & 1.209 & \\
\hline Salivary pH & 2.222 & 0.190 & 25.641 & 0.524 & 6.369 & 1.178 & 34.483 & 0.031 & 2.331 & 0.604 & 9.009 & 0.220 \\
\hline Lactobacilli (log) & 1.142 & 0.864 & 1.511 & 0.351 & 1.152 & 0.964 & 1.376 & 0.119 & 1.013 & 0.887 & 1.158 & 0.847 \\
\hline Total streptococci (log) & 1.594 & 0.188 & 13.494 & 0.669 & 1.859 & 0.438 & 7.893 & 0.401 & 1.095 & 0.352 & 3.406 & 0.875 \\
\hline S. mutans $(\log )$ & 1.337 & 0.868 & 2.060 & 0.188 & 1.096 & 0.880 & 1.364 & 0.413 & 1.259 & 1.045 & 1.517 & 0.015 \\
\hline Fluoride dentifrice & 2.402 & 0.863 & 6.688 & 0.093 & 0.614 & 0.293 & 1.288 & 0.197 & 0.919 & 0.529 & 1.596 & 0.764 \\
\hline Fluoride varnish & 0.803 & 0.451 & 1.428 & 0.455 & 0.914 & 0.631 & 1.323 & 0.633 & 0.994 & 0.749 & 1.318 & 0.965 \\
\hline Fluoride mouth rinse & 1.122 & 0.369 & 3.409 & 0.839 & 1.184 & 0.583 & 2.403 & 0.641 & 0.892 & 0.511 & 1.556 & 0.687 \\
\hline Juice intake & 1.162 & 0.600 & 2.254 & 0.656 & 1.092 & 0.699 & 1.706 & 0.699 & 1.353 & 0.969 & 1.890 & 0.076 \\
\hline Sweet snack intake & 0.751 & 0.314 & 1.796 & 0.519 & 0.686 & 0.380 & 1.237 & 0.210 & 0.778 & 0.499 & 1.213 & 0.268 \\
\hline Regular check-ups & 0.300 & 0.037 & 2.432 & 0.260 & 0.803 & 0.307 & 2.101 & 0.655 & 1.024 & 0.497 & 2.112 & 0.948 \\
\hline $\begin{array}{l}\text { Dental carries in } \\
\text { deciduous teeth }+/-\end{array}$ & 0.454 & 0.130 & 1.588 & 0.216 & 1.117 & 0.435 & 2.870 & 0.818 & 2.262 & 1.024 & 4.996 & 0.043 \\
\hline Gender & 1.193 & 0.418 & 3.402 & 0.741 & 1.247 & 0.624 & 2.492 & 0.533 & 1.821 & 1.048 & 3.162 & 0.033 \\
\hline
\end{tabular}

juice intake, the presence or absence of dental caries in deciduous teeth, and gender, had statistically significant correlations with the incidence of new dental caries. Table 4 shows the multivariate-adjusted odds ratios by results of logistic regression analysis of the risk factors for dental caries. At age 6, no factors were associated with the incidence of new dental caries. At age 7, salivary $\mathrm{pH}$ had a statistically significant correlation with the incidence of new dental caries. At age 8 , by multivariate adjusted odds ratios, the salivary level of MS, the presence or absence of dental caries in deciduous teeth and gender, had statistically significant correlations with the incidence of new dental caries.

\section{Discussion}

Mutans streptococci have been regarded as a key factor in the incidence of dental caries ${ }^{20)}$. Previous studies showed that subjects having high MS and LB levels in saliva are at high risk for dental caries ${ }^{21)}$. In our study, we confirmed the importance of MS 
and LB as a risk factor for dental caries in children and our results are consistent with other reports ${ }^{1,8)}$ although a part of the results might be due to the more skewed distribution of subjects in df or DMF indexes for MS and LB levels in salivary level.

Two of epidemiological studies have used the commercially available kit, Dentocult $\mathrm{SM}^{\mathrm{TM}}{ }^{22,23)}$, this method is very convenient. However, accuracy for detecting MS is questionable. In our study, we used modified MSB agar medium, because combinational used Dentocult SM was semi quantitative. The precise revaluation was necessary for our analysis. Growth of MS is higher than that in conventional MS containing $0.25 \mathrm{U}$ Bacitracin (MSB) agar medium ${ }^{24}$. In young children, early colonization of MS and plaque accumulation on anterior buccal surfaces ${ }^{25,26)}$ have been shown to be strongly associated with caries development. Similar research has found that MS in plaque using Dentocult $\mathrm{SM}^{\mathrm{TM}}$ and past caries experiences at base line were the best predictors for the incidence of new dental caries in children ${ }^{11)}$. Information about fluoride use at age 2 years was thought to measure habits affecting dental health within the family, and consequently, to be associated with development of caries. Our finding that fluoride has no predictive value for caries is in line with results found for 1 to 3 year olds ${ }^{27)}$. The correlation between fluoride usage and the new incidence of dental caries is not statistically significant. Although this result disagrees with findings on fluoride-induced prevention of dental caries in some reports ${ }^{5,28)}$ it is consistent with other studies ${ }^{29,30)}$.

By the results in this study, we agree the suggest that high consumption of carbonated soft drinks is a risk indicator for dental caries in young children and should be discouraged ${ }^{31)}$. Prediction models have also been based on other factors such as daily candy intake or sugar-containing soft drinks ${ }^{32}$. However, the ability of fluoride to prevent dental caries was definite.

And in this study, gender has statistically significant correlations with the incidence of new dental caries, its reason was that girls grow up earlier than boys, and permanent teeth of girl have early the risk for dental caries. The caries in deciduous teeth had also the correlations with the incidence of new dental caries by this results, it's necessary the prevalence of dental caries in young children.

In conclusion, the results of our study are consistent with many longitudinal studies on caries and salivary MS and our results suggest that these tests may be useful for predicting caries in primary and mixed dentition.

\section{References}

1) Petersson, G.H., Fure, S., Twetman, S. and Bratthall, D.: Comparing caries risk factors and risk profiles between children and elderly. Swed Dent J 28: 119128, 2004.

2) Pienihäkkinen, K., Jokela, J. and Alanen, P.: Assessment of caries risk in preschool children. Caries Res 38: 156-162, 2004.

3) Marsh, P.D.: The role of chemostats in the evaluation of antimicrobial agents for use in dental products. Microbial Ecology in Health and Disease 6: 147149, 1993.

4) Disney, J.A., Graves, R.C., Stamm, J.W., Bohannan, H.M., Abernathy, J.R. and Zack, D.D.: The University of North Carolina Caries Risk Assessment study: further developments in caries risk prediction. Community Dent Oral Epidemiol 20: 64-75, 1992.

5) Pienihakkinen, K., Jokela, J. and Alanen, P.: Riskbased early prevention in comparison with routine prevention of dental caries: a 7-year follow-up of a controlled clinical trial; clinical and economic aspects. BMC Oral Health 5: 2, 2005.

6) Venugopal, T., Kulkarni, V.S., Nerurker, R.A., Damle, S.G. and Patnekar, P.N.: Epidemiological study of dental caries. Indian J Pediatr 65: 883-889, 1998.

7) Harkane, T., Larmas, M.A., Virtanen, J.I. and Arjas, E.: Applying modern survival analysis methods to longitudinal dental caries studies. J Dent Res 81: 144-148, 2002.

8) Oncag, O., Alpoz, A.R. and Eronat, C.: Salivary Streptococcus mutans, Lactobacilli levels and buffer capacity in children with esophageal burns. J Clin Pediatr Dent 24: 147-151, 2000.

9) Thibodeau, E.A. and O'Sullivan, D.M.: Salivary mutans streptococci and caries development in the primary and mixed dentitions of children. Community Dent Oral Epidemiol 27: 406-412, 1999.

10) Hamada, S., Masuda, N., Ooshima, T., Sobue, S. and Kotani, S.: Epidemiological survey of Streptococcus mutans among Japanese children. Identification and serological typing of the isolated strains. Jpn $J$ Microbiol 20: 33-44, 1976.

11) Demers, M., Brodeur, J.M., Mouton, C., Simard, P.L., Trahan, L. and Veilleux, G.: A multivariate model to predict caries increment in Montreal children aged 5 years. Community Dent Health 9: 273-281, 1992.

12) Wan, A.K., Seow, W.K., Purdie, D.M., Bird, P.S., Walsh, L.J. and Tudehope, D.I.: A longitudinal study of Streptococcus mutans colonization in infants after tooth eruption. J Dent Res 82: 504-508, 2003.

13) Nomura, Y., Senpuku, H., Hanada, N. and Kumagai, T.: Mutans streptococci and Lactobacillus as risk factors for dental caries in 12-year-old children. Jpn J Infect Dis 54: 43-45, 2001. 
14) Bjorndal, L. and Larsen, T.: Changes in the cultivable flora in deep carious lesions following a stepwise excavation procedure. Caries Res 34: 502-508, 2000.

15) Nishikawara, F., Nomura, Y., Tamaki, Y., Katsumura, S., Asada, Y., Hanada, N. and Petersen, P.E.: Fluoridecontaining mouthrinses in three European countries. Pediatric Dent J 16: 118-122, 1996.

16) Tamaki, Y., Nomura, Y., Nishikawara, F., Motegi, M., Teraoka, K., Arakawa, H., Tsurumoto, A. and Hanada, N.: Correlation between patient satisfaction and dental clinic credibility in regular dental checkups in Japan. J Oral Sci 47: 97-103, 2005.

17) Barmes, D.E. and Infirri, J.S.: WHO activities in oral epidemiology. Community Dent Oral Epidemiol 5: 22-29, 1977.

18) Juárez Tomás, M.S., Bru de Labanda, E., de Ruiz Holgado, A.P. and Nader-Macías, M.E.: Estimation of vaginal probiotic lactobacilli growth parameters with the application of the Gompertz model. Can J Microbiol 48: 82-92, 2002.

19) Ida, H., Hanada, N., Sato, T. and Yoshikawa, E.: Clinical Biology of the Mutans Streptococci. Quintessence Publishing, Tokyo, 2003, pp.82-89.

20) Fitzgerald, R.J. and Keyes, P.H.: Demonstration of the etiologic role of streptococci in experimental caries in the hamster. J Am Dent Assoc 61: 9-19, 1996.

21) Llena-Puy, M.C., Montanana-Llorens, C. and FornerNavarro, L.: Cariogenic oral flora and its relation to dental caries. ASDC J Dent Child 67: 42-46, 2000.

22) Shi, S., Liang, Q., Hayashi, Y., Yakushiji, M. and Machida, Y.: The relationship between caries activity and the status of dental caries application of the Dentocult SM method. Chin J Dent Res 1: 52-55, 1998.

23) Shi, S., Deng, Q., Hayashi, Y., Yakushiji, M., Machida,
Y. and Liang, Q.: A follow-up study on three caries activity tests. J Clin Pediatr Dent 27: 359-364, 2003.

24) Gold, O.G., Jordan, H.V. and van Houte, J.: A selective medium for Streptococcus mutans. Arch Oral Biol 18: 1357-1364, 1973.

25) Kohler, B., Andreen, I. and Jonsson, B.: The earlier the colonization by mutans streptococci, the higher the caries prevalence at 4 years of age. Oral Microbiol Immunol 3: 14-17, 1998.

26) Alaluusua, S. and Malmivirta, R.: Early plaque accumulation: a sign for caries risk in young children. Community Dent Oral Epidemiol 22: 273-276, 1994.

27) Grindefjord, M., Dahllof, G., Nilsson, B. and Modeer, T.: Stepwise prediction of dental caries in children up to 3.5 years of age. Caries Res 30: 256-266, 1996.

28) Vignarajah, S. and Williams, G.A.: Prevalence of dental caries and enamel defects in the primary dentition of Antiguan pre-school children aged 3-4 years including an assessment of their habits. Community Dent Health 9: 349-360, 1992.

29) Davies, G.M., Duxbury, J.T., Boothman, N.J., Davies, R.M. and Blinkhorn, A.S.: A staged intervention dental health promotion programme to reduce early childhood caries. Community Dent Health 22: 118122, 2005.

30) Sköld, U.M.: On caries prevalence and school-based fluoride programmes in Swedish adolescents. Swed Dent J Suppl 178: 11-75, 2005.

31) Sohn, W., Burt, B.A. and Sowers, M.R.: Carbonated soft drinks and dental caries in the primary dentition. J Dent Res 85: 262-266, 2006.

32) Harris, R., Nicoll, A.D., Adair, P.M. and Pine, C.M.: Risk factors for dental caries in young children: a systematic review of the literature. Community Dent Health 21: 71-85, 2004. 